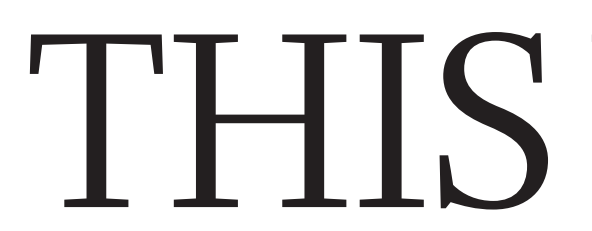

EDITORIALS
ETHICS Will future scientists take exception to your experiments? $\mathbf{p} . \mathbf{1 3 2}$
WORLD VIEW Moving on from science for the sake of it $\mathbf{p} .133$
PLUMAGE First bird

Archaeopteryx had black feathers $\mathbf{p . 1 3 5}$

\title{
Facing up to flu
}

\section{The potential for mutant-flu research to improve public health any time soon has been exaggerated. Timely production of sufficient vaccine remains the biggest challenge.}

A mid the scientific controversy over lab-created strains of the $\mathrm{H} 5 \mathrm{~N} 1$ avian influenza virus that can skip between mammals, it is easy to lose sight of an important public-health question: what will help the wider world to prepare for a flu pandemic? The question is crucial, because when it comes to setting priorities, the fuss over how to regulate the controversial research must not be allowed to distract from a much bigger concern. The world is ill-prepared for a severe flu pandemic of any type. In particular, it cannot yet produce enough vaccine to protect more than just a small proportion of people.

The problem was demonstrated by the 2009 pandemic of H1N1 flu. Vaccines only became available months after the outbreak began, and after the first wave had peaked in many countries. Health systems were stretched despite the relative mildness of the pandemic. The mutantflu research does nothing to prevent a repeat of this situation.

Research to create mammalian-transmissible strains is vital basic science that could deepen our understanding of flu viruses, and of what allows a virus to jump from other species and spread easily in humans. These insights may one day produce better ways to tackle a pandemic, including ones we cannot picture today. But scientists need to be more modest and realistic with their claims about the short-term public-health benefits of such research, and provide better explanations that include the caveats.

For example, many commentators say that the biggest public-health benefit promised by the research is in the field of disease surveillance. The experiments reveal one combination of mutations that allowed the $\mathrm{H} 5 \mathrm{~N} 1$ virus to jump between species and then spread; in theory, animal-health experts can now watch out for these mutations in affected animals such as pigs and birds.

In practice, the immediate benefits are minimal. Surveillance of influenza in animals is slow and patchy at best, and follow-up sequencing of samples more so. And the mutations that we know about are likely to be outnumbered by those about which we are still ignorant.

Consider $\mathrm{H} 5 \mathrm{~N} 1$ in pigs. There is almost no systematic flu surveillance in the animals (see Nature 459, 894-895; 2009). Infections are infrequent, symptoms are mild and the pig industry is concerned that talk of swine flu could unfairly taint the image of pork. As a result, the world's one billion or so pigs have yielded partial DNA sequences of just $24 \mathrm{H} 5 \mathrm{~N} 1$ isolates, meaning that were a pandemic $\mathrm{H} 5 \mathrm{~N} 1$ virus to emerge from pigs, just as H1N1 did in 2009, there would be little or no possibility of detecting it in advance.

That does not mean that the idea of using the mutant-flu research to improve surveillance is without merit; far from it. Further work could yield a more comprehensive bank of mutations, and greater investment could create specialized centres to screen more samples in affected countries, in real time. Improving flu-virus surveillance should be a public-health priority, but international groups and governments have, in the past, been reluctant to fund it adequately. If the world is serious about preparing for a pandemic, this must change.

Done properly, surveillance could one day give early warning of an approaching pandemic. What then?

At present, such advance knowledge would make little difference to the world's limited abilities to manufacture and distribute vaccines. Current techniques can produce vaccine only six months after a pandemic emerges. Doing so faster and in much larger quantities is the

"The mutant-flu studies offer no serious immediate application in vaccine research." most urgent public-health priority when it comes to planning for the next pandemic.

The mutant-flu studies contribute little to this goal. They offer no serious immediate application in vaccine research (see page 142). Any benefits to drug development - which are important, but less so than churning out vaccine for a pandemic - are more likely to flow from longer-term basic research. The mutant-flu work could certainly help this research. Yet the work itself carries a risk. An accidental, or intentional, release of the mutant viruses from a lab could spark an $\mathrm{H} 5 \mathrm{~N} 1$ pandemic that we are currently in no position to mitigate.

The fact that the risks seem to far outweigh the public-health benefits of the research, at least in the short term, means that there is no need to rush headlong into an expansion of the work. Rather, regulators and flu researchers must take whatever time they need to decide the best way for such work to proceed safely.

\section{Gas and air}

\section{Natural-gas operations could leak enough methane to tarnish their clean image.}

$\mathrm{H}$ ow clean is natural gas? Although it is often lumped in with coal and oil, many in the energy industry are at pains to point out that burning gas to generate electricity produces fewer greenhouse-gas emissions than does burning other fossil fuels. Certainly, countries claim reductions in carbon emissions when they switch from coal to gas, as Britain did on a large scale in the 1990s. The growing popularity of shale formations as a source of gas has re-energized the debate over its environmental impact. To release the gas, engineers must split the rock by injecting fluid under high pressure, a process called fracking. Last year, researchers from Cornell University in Ithaca, New York, said that with this taken into account, carbon emissions associated with shale gas were no better - or were worse - than those from coal.

Industry maintains that the problem has been exaggerated, and many scientists agree. Sorting fact from fiction has been difficult, however, because nobody had any independent data - until now. 
As discussed on page 139, a study led by scientists from the US National Oceanic and Atmospheric Administration (NOAA), headquartered in Washington DC, and the University of Colorado in Boulder looked at methane and other emissions from a natural-gas field north of Denver, where fracking methods are used to open up sand formations.

They estimated cumulative emissions from the field using not industry reports or conceptual models, but concentrations of pollutants in air samples. This is important because the atmosphere does not misrepresent data or make mistakes; nor does it bend to ideology or political will.

The data suggest that methane emissions from natural-gas operations could be substantially higher - and so be worse for global warming than was thought. At works in the Denver-Julesburg Basin, methane emissions were roughly double the official estimate.

This will by no means settle the debate. The NOAA scientists had to make assumptions to convert atmospheric data to cumulative emissions from a vast energy complex. They readily acknowledge substantial uncertainty in their calculations, and estimate that between $2 \%$ and $8 \%$ of the methane produced from wells in the Denver-Julesburg Basin is lost to the atmosphere, with a best guess of $4 \%$.

These numbers, which are higher than estimates from Cornell and the US Environmental Protection Agency (EPA), should serve as a red flag to the gas industry, policy-makers and the academic community. Researchers will need to confirm the findings, reduce the uncertainties and determine emissions from other locations. But the issue clearly warrants attention. The study should also be a reminder that although it is necessary for the industry to collect data on its practices and run calculations, independent monitoring and verification are needed.
More generally, the study further complicates understanding of what is considered the world's cleanest fossil fuel. Many in industry and science have talked about using gas as a bridge fuel for the transition from coal to cleaner sources of electricity, but the picture is unclear.

In many places, including the United States, gas-fired electricity is

"Emissions from natural-gas operations could besubstantially higher than was thought." likely to be significantly cleaner than coal in terms of carbon emissions even with the extra methane leakage - if only because newer gas-fired plants are much more efficient than the behemoths that provide most coal-fired electric generation. By contrast, a modelling study by Tom Wigley, a climate scientist at the US National Center for Atmospheric Research in Boulder, last year found that switching from coal to natural gas would actually increase global temperatures for decades, by reducing emissions of pollutants that reflect solar radiation back into space (T. M. L. Wigley Climatic Change 108, 601-608; 2011). In the end, natural gas might be preferable to coal just because it reduces harmful air pollution. But the climatic benefits are murky at best.

The good news is that the natural-gas industry has the capacity to reduce methane leakage by cleaning up its operations. Technologies are already available to capture methane during fracking rather than venting it into the atmosphere when bringing a gas well online. As it happens, the EPA is currently considering mandatory regulations that encourage such activities by limiting various pollutants from naturalgas operations. These regulations would indirectly reduce methane emissions, and the EPA must press forward.
Hypocritical oaths History judges some research as unethical, despite approval at the time.

$\mathrm{E}$ thical boundaries for experiments on humans can be stated very simply. "The limits of justifiable experimentation upon our fellow creatures are well and clearly defined," Canadian physician William Osler, one of the grand old men of US medicine, wrote more than a century ago. "For man absolute safety and full consent are the conditions which make such tests allowable."

Although US standards have evolved, the concepts of informed consent and safety still underpin research on humans. How, then, could leading health officials in the United States approve a set of barbarous experiments in the 1940s, in which government physicians intentionally infected hundreds of people in Guatemala with venereal diseases?

The people were labelled volunteers, but evidence suggests that they did not provide consent. And as the News Feature on page 148 shows, records indicate that some of the people exposed to syphilis, gonorrhea and chancroid subsequently went untreated.

Such recklessness seems abhorrent now, but this is far from an isolated case. In 1941, US physician William Black infected children, including a 12-month-old baby, with the herpes virus. When Black submitted his paper to the Journal of Experimental Medicine, it was rejected. Francis Peyton Rous, the journal's editor, told Black that his work was "an abuse of power". Nonetheless, the paper was published soon after by the Journal of Pediatrics.

And Rous was less concerned about a study in which residents of a psychiatric hospital in Michigan were infected with influenza, even though it seems that at least some of the patients could not give their consent. It might be tempting to explain away such research abuses as the work of rogue scientists, but the Michigan study was conducted by a leading researcher of the time, Thomas Francis Jr, and his young colleague, Jonas Salk, who went on to develop the polio vaccine.
And two decades later, in 1963, a team run by Chester Southam injected tumour cells into extremely infirm patients at the Jewish Hospital for Chronic Disease in New York without informing them that the shots contained cancer. Southam was later put on probation by the New York State medical licensing board, but many researchers defended the work and he was later elected president of the American Association for Cancer Research.

What kind of work deemed as accepted today will be denounced by future generations? The question is one that all researchers should bear in mind, because history may judge them more harshly than their peers do. One example could be denial of treatment to sick people through the use of placebos in clinical trials and the ways in which some of these trials are carried out in developing nations, amid accusations of abuse of poor, uneducated participants. Broadening to other types of research, attitudes to work on embryonic stem cells may harden. And future generations may extend the protection currently in place for humans to cover other species, such as chimpanzees.

In the case of chimpanzees, Gabon and the United States are the only nations known to still use them for research, and a committee of the US National Research Council last year recommended that the United States should sharply limit their use, but stopped short of calling for a complete ban. Meanwhile, some researchers have been able to avoid bans in their own countries by travelling to the United States. Since 2005, foreign scientists have conducted at least 27 experiments at US chimpanzee centres (see Nature 474, 268-271; 2011).

There is, of course, clear water between the Guatemalan experiments and chimpanzee research. The Guatemala research was illegal, even in the 1940s, and most of the data did not prove useful and went unpublished. Still, as with research on embryonic stem cells, there is considerable debate about the ethics of using chimpanzees as experimental subjects. In these and other cases, nations would do well to heed some of the lessons that emerged from the investigation of the $\rightarrow$ NATURE.COM To comment online, click on Editorials at: go.nature.com/xhunqu experiments in Guatemala. Governments and other funders of research must exert full oversight, provide as much transparency as possible and ensure that regulations are clear, strong and evolve with the times. 